\title{
Risk Factors of Non-Communicable Diseases (NCD) among Students of Junior College in Wardha District
}

\author{
Mayur Anil Nimbalkar ${ }^{1}$, Swarupa Chakole ${ }^{2}$ \\ 1,2 Department of Community Medicine, Datta Meghe Institute of Medical Sciences, \\ Sawangi (Meghe), Wardha, Maharashtra, India.
}

\section{ABSTRACT}

\section{BACKGROUND}

Adolescents constitute around $16 \%$ of the total global population, with an absolute number of 1.2 billion. The rapid psychosocial and sexual changes that occur during the puberty period influence every aspect of teenage life. Such changes make adolescence a unique phase in every life-course and to lay the groundwork for good adult health. Health problems and behaviour problems that arise during adolescence lead to chronic illness and alcohol abuse. Mainly the risk factors are behaviourally acquired and are due to change in lifestyle during adolescent age group. The aetiology of NCDs is multifarious and both genetic and environmental factors play a role.

\section{METHODS}

A cross-sectional college-based study was conducted by using a pre-structured and pre-designed questionnaire in junior colleges in Wardha district among students of 17 - 19 years age group by using the WHO STEPS questionnaires.

\section{RESULTS}

Males were 51 i.e. $28.5 \%$ and females were 149 i.e. $74.5 \%$. In the present study, 7 males i.e. $13.72 \%$ and 22 females $14.76 \%$ were having work related physical activity. 13 males i.e. $25.49 \%$ and 35 females i.e. $23.48 \%$ were exposed to second hand smoke at home at home; 4 males and 31 females were exposed to second smoke at work place. About 44 males are underweight (BMI less than 18.5) and 78 females are the same. Only 7 males have normal weight while 62 females have average weight (BMI $=18.5-24.9$ ). There were zero pre obese and obese participants among males while 7 females are pre obese and 2 females are obese.

\section{CONCLUSIONS}

There was a substantial gap between groups of males and females who believe that excess salt intake is detrimental to the body. There was significant difference in waist / hip ratio of males and females. It means males have lower waist / hip ratio than females. There was significant difference in BMI categories of male and female. More males are underweight compared to females. However, more females are pre-obese and obese.

\section{KEY WORDS}

Non-Communicable Diseases, Determinants of NCD, Junior College, Adolescents
Corresponding Author: Dr. Mayur Nimbalkar, Department of Community Medicine, Datta Meghe Institute of Medical Sciences, Sawangi (Meghe), Wardha, Maharashtra, India.

E-mail:62987m@gmail.com

DOI: $10.14260 / \mathrm{jemds} / 2020 / 705$

How to Cite This Article:

Nimbalkar MA, Chakole S. Risk factors of Non-Communicable Diseases (NCD) among students of junior college in Wardha district. J Evolution Med Dent Sci 2020;9(43):3214-3217, DOI: $10.14260 / \mathrm{jemds} / 2020 / 705$

Submission 26-07-2020,

Peer Review 20-09-2020

Acceptance 26-09-2020,

Published 26-10-2020.

Copyright (C) 2020 Mayur Anil Nimbalkar et al. This is an open access article distributed under Creative Commons Attribution License [Attribution 4.0 International (CC BY 4.0)] 


\section{BACKGROUND}

Adolescents constitute around $16 \%$ of the total global population, with an absolute number of 1.2 billion. Across Asia more than half of all adolescents stay. Exactly, South Asia is home town of adolescents (around 340 million) than any other region. India has 253 million teenagers, about 20.9 per cent of the total population of the world. Around $72 \%$ of the adolescents' population is rural. According to last two censuses adolescent population in urban area declines from $21.9 \%$ in 2001 to $19.2 \%$ in 2011, while in rural areas, it remained more or less same. Adolescence is a key phase of human development \& growth. The rapid psychosocial and sexual changes that occur during the puberty period influence every aspect of teenage life. Such changes make adolescence a unique phase in every life-course and to lay the groundwork for good adult health. Changes in adolescence are responsible for the epidemiological transition from infectious disease to non-communicable conditions. Health problems and behavior problems that arise during adolescence leads to chronic illness and alcohol abuse. According to the WHO, obesity / overweight is one of the most common, yet among the most missed problem of public health in both developed and developing countries. According to World Health Statistic Report 2016, globally there is one in every six adult who is obese / overweight and near about 2.8 million individual die each year due to overweight or obesity. Due to the higher risk of morbidity \& mortality, obesity is now being accepted as a disease in its own right. ${ }^{1}$

Risk factors responsible for NCDs are behavioural factors such as, physical inactivity, tobacco use and metabolic factors such as overweight / obesity, high blood pressure (BP), elevated blood glucose and high cholesterol rates level. Mainly the risk factors are behaviourally acquired and are due to change in lifestyle during adolescent age group. Adolescent life is the era of rapid growth and development of body, mind and social relationships with improvements in behaviours such as sexual maturity and self-independence, with increased exposure to risk behaviours such as unprotected sex, reckless driving and drug abuse ${ }^{2}$

Relatively meek early-life interventions can later have a big impact on disease risk. Later intervention can have a risk of disease contact for groups at risk. Premature life precautionary measures require a long-term outlay but can lead to significant reduction of the risk of disease. Thus they are more probable to be effective at preventing NCDs than inhabitants screening programs that identify the premature stages of disease only after the disease is already established. The aetiology of NCDs is multifarious and both genetic and environmental factors play a role.

\section{Objectives}

1. To study the determinants of NCD among students of junior college in Wardha district.

2. To find out the proportion of excess weight and obesity among adolescents going to college.

3. To find out the dietary habits and physical activity among college going adolescents.

4. To find out predominant determinants of NCD among adolescents.

\section{METHODS}

This is a descriptive cross-sectional study conducted from July 2019 to February 2020 among college going adolescents, using WHO STEPS. ${ }^{3}$ Questionnaires were given to college going students of Wardha district. Study sample was selected by systemic random sampling. We enlisted all the junior colleges and by random cheat method two colleges were selected. We had taken permission of principals of those collages to conduct the study. Then we enumerated all the classes. According to the sample size, a bunch of students were selected from each class systematically i.e. $x$.

$\mathrm{X}=$ sample size / no. of classes.

Systemic random method has been used, and according to the $\mathrm{x}$, every $\mathrm{n}^{\text {th }}$ student has been enrolled with his / her due consent.

$\mathrm{N}=$ strength of that class / sample size allocated to that class.

\section{Sample Size Calculation}

For descriptive cross-sectional studies with confidence interval of $95 \%$ and design effect of $5 \%$ and overall average prevalence of NCD in adolescent in India as $15 \%$, sample size will be

$n=\frac{\mathrm{Z} 2 \mathrm{pq}}{\mathrm{d}^{2}}$

$1.96 * 1.96 * .15 * .85 / .0025$

$=195$

$\cong 200$.

\section{Inclusion Criteria}

Students of the given junior colleges. Out of which those who are agreeable to take part in the study and are ready to give their consent for their estimation

\section{Data Collection Technique}

Data collection was carried out by the researcher. At first, the college higher authority and study participants were explained about the study objectives, purpose, study tool and the ethical aspects of the research. After obtaining written consent of the college higher authority, students were interviewed in local language. Body weight was measured at nearest $100 \mathrm{~g}$ using a calibrated portable scale, with light weight clothing and no shoes. ${ }^{4}$ Height to the nearest $\mathrm{cm}$ with the person in complete standing posture without shoes using a stadiometer. ${ }^{4} \mathrm{BMI}$ was calculated as using $\mathrm{WHO}$ anthro plus software. ${ }^{4}$

\section{Statistical Analysis}

Statistical analysis was conducted using inferential and descriptive statistics using $\mathrm{Z}$ test, Chi sq. test, and Fischer's exact test and softwares used were SPSS ver. 24.0 and GraphPad Prism 7.01. A p value of less than 0.05 was considered significant. 


\section{Definition of Variables}

Obesity - Obesity is an excessive \& abnormal accumulation of body fat that typically reaches 20 per cent or more of the average body weight of a person. ${ }^{5}$

Body Mass Index (BMI) - The weight of a person in kilograms (kg) divided by their height in meters (m) squared is an important index for comparing body weight to height. Overweight and obesity are classified as children aged between 5 - 19 years, according to the Centers for Disease Control and Prevention (CDC). Obesity is described as a BMI for children / teens of the same age and sex at or above the 95th percentile. ${ }^{6}$ Physical activity, health, and exercise defined as physical activity: any body movement / action resulting in energy expenditure (e.g. walking, stepping). Physical activity involves play, games, sports, etc. for children and young people. ${ }^{7}$ Light exercise involves slow walking, sitting with a screen, standing light work (cooking, washing dishes) and fishing, sitting and playing most instruments. Moderate exercise / sports intensity: Includes very brisk walking (4 $\mathrm{mph}$ ), heavy cleaning (washing windows, vacuuming, mopping), light bicycling (10 - $12 \mathrm{mph}$ ), basketball, table tennis, bowling, aerobic dance, etc. Vigorous intensity exercise / sports): Involves running, $6 \mathrm{mph}$ jogging, shoveling, heavy load carrying, fast bicycling (14 - $16 \mathrm{mph})$, cricket, singles soccer and tennis, hockey, volleyball, hand ball athletics etc. ${ }^{8}$

Adolescent ${ }^{9}$ - WHO describes 'Adolescents' as individuals in the age group of $10-19$ and 'Youth' as the age group of $15-24$ years.

NCD - Non-communicable diseases, also known as chronic diseases, tend to be long-lasting and arise from a combination of factors in biology, metabolism, climate and behaviour. Cardiovascular disorders (such as heart attacks and strokes), cancers, chronic respiratory conditions (such as chronic obstructive pulmonary disease and asthma) and diabetes are the major forms of NCDs. ${ }^{10}$

Determinants 11 - An element that identifies or determines the nature of something or that fixes or conditions an outcome e.g., education level as a determinant of income.

\section{RESULTS}

\begin{tabular}{|c|c|c|c|c|c|}
\hline \multicolumn{5}{|c|}{ Diet } & \multirow{3}{*}{$\begin{array}{c}\text { Z Test / } \\
\text { Fischer's Exact } \\
\text { est. }\end{array}$} \\
\hline Age group & & Male & & emale & \\
\hline $17-19$ & $N(51)$ & Mean / \% & $N(149)$ & Mean / \% & \\
\hline $\begin{array}{l}\text { Mean no. of days of fruit } \\
\text { consumption / week }\end{array}$ & 51 & $1.35 \pm 1.9$ & 149 & $1.73 \pm 1.38$ & $\begin{array}{c}\mathrm{Z}=1.54 \\
\mathrm{P}=0.12 \mathrm{NS}\end{array}$ \\
\hline $\begin{array}{c}\text { Mean no. of days of } \\
\text { vegetables consumption / } \\
\text { week }\end{array}$ & 51 & $4.9 \pm 1.40$ & 149 & $5.32 \pm 1.24$ & $\begin{array}{c}\mathrm{Z}=2.00 \\
\mathrm{P}=0.46, \mathrm{~S}\end{array}$ \\
\hline$\%$ Adding salt while eating & 44 & 86.27 & 135 & 90.60 & $0.37, \mathrm{NS}$ \\
\hline $\begin{array}{l}\% \text { Consuming processed } \\
\text { food high in salt }\end{array}$ & 46 & 90.19 & 143 & 95.97 & 5, NS \\
\hline $\begin{array}{c}\% \text { Thinks salt is injurious to } \\
\text { health }\end{array}$ & 28 & 54.90 & 111 & 74.49 & $0.007, \mathrm{~S}$ \\
\hline
\end{tabular}

Among the study participants, 10 were male. $60 \%$ were in upper class; 11 i.e. $21.56 \%$ were in upper middle class; 3 i.e. $5.88 \%$ were in lower middle class and $0 \%$ were in lower class. There were 21 females. $14.09 \%$ were in upper class; 49 i.e.
$32.88 \%$ were in upper middle class. 76 i.e. $51.00 \%$ were in middle class; 03 i.e. $2.01 \%$ were in lower middle class and $0 \%$ were in lower class.

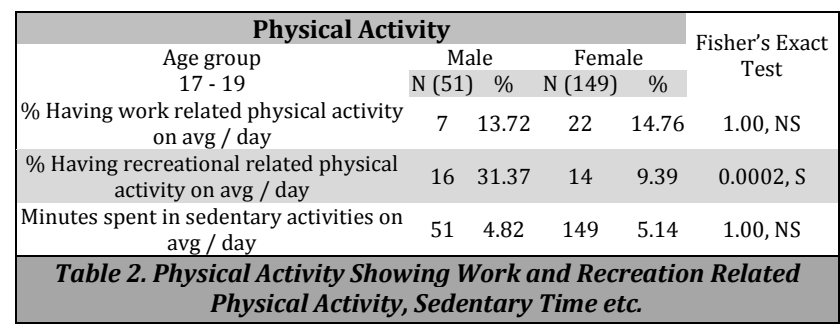

\begin{tabular}{|c|c|c|c|c|c|}
\hline \multicolumn{5}{|c|}{ Physical Measurement } & \multirow[b]{3}{*}{ Z-Value } \\
\hline \multirow{2}{*}{$\begin{array}{c}\text { Age group } \\
17-19\end{array}$} & \multicolumn{2}{|c|}{ Male } & \multicolumn{2}{|c|}{ Female } & \\
\hline & $\mathrm{N}(51)$ & Mean / \% & N (149) & $\begin{array}{c}\text { Mean / } \\
\%\end{array}$ & \\
\hline Mean systolic blood pressure & 51 & $106 \pm 4.26$ & 149 & $\begin{array}{c}105 \pm \\
4.70\end{array}$ & $\begin{array}{c}\mathrm{Z}=1.43 \\
\mathrm{P}=0.13, \mathrm{NS}\end{array}$ \\
\hline $\begin{array}{c}\% \text { Having blood pressure > } \\
140 / 90 \mathrm{~mm} \mathrm{hg}\end{array}$ & 0 & 0 & 0 & 0 & \\
\hline Mean Waist / Hip Ratio & 51 & $\begin{array}{c}0.844 \pm \\
0.05\end{array}$ & 149 & $\begin{array}{c}0.774 \pm \\
0.05\end{array}$ & $\begin{array}{c}Z=7.87 \\
P=0.0001, S\end{array}$ \\
\hline
\end{tabular}

\begin{tabular}{|c|c|c|c|c|c|}
\hline \multicolumn{5}{|c|}{ BMI Classification } & \multirow{4}{*}{$\begin{array}{c}\text { Chi sq. Test } \\
x^{2}=18.81\end{array}$} \\
\hline BMI & & & & male & \\
\hline Classification $^{12}$ & $\mathrm{~N}$ & $\%$ & $\mathrm{~N}$ & $\%$ & \\
\hline Underweight (BMI = < 18.5) & 44 & $86.27 \%$ & 78 & $52.34 \%$ & \\
\hline $\begin{array}{c}\text { Normal weight } \\
18.5-22.9)\end{array}(\mathrm{BMI}=$ & 5 & $9.80 \%$ & 53 & $35.57 \%$ & \\
\hline Pre-obese $(\mathrm{BMI}=23.0-24.9)$ & 2 & $3.92 \%$ & & $5.36 \%$ & $P=0.0001$ \\
\hline Obese (BMI $\geq 25.0$ ) & 0 & $0 \%$ & 9 & $6.04 \%$ & Significant \\
\hline
\end{tabular}

\begin{tabular}{|c|c|c|c|c|c|c|c|c|}
\hline \multicolumn{8}{|c|}{ Waist Hip Ratio } & \multirow[b]{3}{*}{$\mathrm{X}^{2}$-Value } \\
\hline \multirow[b]{2}{*}{$\begin{array}{c}\text { Age } \\
\text { group }\end{array}$} & \multicolumn{4}{|c|}{ Male } & \multicolumn{3}{|c|}{ Female } & \\
\hline & $\mathrm{n}$ & $\begin{array}{l}\text { Low } \\
\text { (0.95 or } \\
\text { lower) }\end{array}$ & $\begin{array}{c}\text { Moderat } \\
r(0.96- \\
1.0)\end{array}$ & $\begin{array}{l}\text { High (1.0 } \\
\text { or } \\
\text { higher) }\end{array}$ & $\begin{array}{cc} & \text { Low } \\
\mathrm{n} & (0.80 \text { or } \\
& \text { lower })\end{array}$ & $\begin{array}{c}\text { Moderate } \\
(0.81- \\
0.85)\end{array}$ & $\begin{array}{c}\text { High } \\
\text { ( } 0.86 \text { or } \\
\text { higher) }\end{array}$ & \\
\hline $\begin{array}{c}17- \\
19\end{array}$ & 51 & $\begin{array}{c}51 \\
(100 \\
\%)\end{array}$ & $\begin{array}{c}0 \\
(0 \%)\end{array}$ & $\begin{array}{c}0 \\
(0 \%)\end{array}$ & $\begin{array}{c}120 \\
149(80.53 \\
\%)\end{array}$ & $\begin{array}{c}20 \\
(13.42 \%)\end{array}$ & $\begin{array}{c}9 \\
(6.04 \%)\end{array}$ & $\begin{array}{l}X^{2}=43.09 \\
P=0.0001, S\end{array}$ \\
\hline & & & $\begin{array}{l}\text { We 5. I } \\
\text { Waist }\end{array}$ & Hip & $\begin{array}{l}\text { atio Shou } \\
\text { imong Ma }\end{array}$ & g Cat & $\begin{array}{l}\text { ries of } \\
\text { ale }\end{array}$ & \\
\hline
\end{tabular}

\section{DISCUSSION}

Objective of the study is to determine the prevalence of NCD among adolescent and to know the predominant determinants of NCD among adolescents. To cover the sample size of 200, systematic random sampling was used in which 124 students are from new arts, commerce and science college and 76 are from J.B. college of science.

In the present study total number of participants are 200: The distribution of the study participants according to the gender, males are 51 i.e. $28.5 \%$ and female are 149 ie $74.5 \%$.

In the present study the mean day of fruits consumption per week in boys was found to be $1.35 \pm 1.92$ and in girls was $1.73 \pm 1.38$. The mean day of vegetable consumption per week in boys was found to be $4.9 \pm 1.40$ and in girls was $5.32 \pm 1.24$. $86.27 \%$ males were found to add salt while eating and 90.60 $\%$ females was found doing the same. $90.19 \%$ males consumes processed food high in salt and $95.97 \%$ females was found doing the same. While $54.90 \%$ males thinks salt is injurious to health and $74.49 \%$ females thinks the same.

In present study 7 males ie $13.72 \%$ and 22 females 14.76 $\%$ were having work related physical activity. 
In the present study no one was found using tobacco in smoke or smoke less form. However 13 males i.e. $25.49 \%$ and 35 females i.e. $23.48 \%$ were exposed to second hand smoking at home and 4 males and 31 females were exposed to second smoke at work place.

In the present study the mean systolic blood pressure in males was found to be $1.6 \pm 4.26$ and in females it was $105 \pm$ 4.70. The mean waist / hip ratio in males was $0.844 \pm 0.05$ and in females was $0.774 \pm 0.05$. About 44 males are underweight (BMI less than 18.5) and 78 females are the same. Only 7 males have normal weight while 62 females have normal weight $(\mathrm{BMI}=18.5$ to 24.9). There were zero pre obese and obese participants among males while 7 females are pre obese and 2 female are obese.

\section{CONCLUSIONS}

There was significant difference among males and females who think excess salt consumption is injurious to the health. It means females are more aware about the injurious nature of excess salt consumption. There was significant difference among males and females who were having recreational activities. It means males are having more recreational activity than females. Females should take at least 5 servings of fruits and / or vegetables per day, and reduce fat in their diet, start doing physical exercises. There was significant difference in waist / hip ratio of males and females. It means males have lower waist / hip ratio than females. There was significant difference in BMI categories of male and female. It means more males are underweight than females. However more number of females are pre-obese and obese.

\section{Recommendations}

1. Colleges should provide opportunities for all students to involve in at least 30 minutes of moderate to vigorous physical activity every day.

2. Parents must play their part by encouraging their children to eat healthy foods and perform regular physical activity by limiting their time (less than two hours a day) on sedentary activities.

\section{Limitations}

1. The study was participant oriented. Responses to questions were influenced by levels of understanding and knowledge of the participants.

2. Observations may have been different if the study was community based.

3. Recall bias might be a limitation of the study.
4. The present study was conducted in a private college from an urban area; however coverage of governmental school from rural or urban area will provide more insight.

Data sharing statement provided by the authors is available with the full text of this article at jemds.com.

Financial or other competing interests: None.

Disclosure forms provided by the authors are available with the full text of this article at jemds.com.

Authors would like to thank the principal and teachers of their respective junior colleges. We are also thankful to all the participants for their co-operation.

Institutional Ethics Committee approval [DMIMS (DU) / IEC / Sept 2019 / 8320] was obtained from the Ethics Committee of DMIMS University.

\section{REFERENCES}

[1] Ramadass S, Gupta SK, Nongkynrih B. Adolescent health in urban India. J Family Med Prim Care 2017;6(3):468-76.

[2] Bhagyalaxmi A, Atul T, Shikha J. Prevalence of risk factors of non-communicable diseases in a district of Gujarat, India. J Heal Popul Nutr 2013;31(1):78-85.

[3] Stepwise WHO. WHO STEPS Instrument. https://www.who.int/ncds/surveillance/steps/STEPS_I nstrument_v2.1.pdf

[4] Puwar T, Saxena D, Yasobant S, et al. Noncommunicable diseases among school-going adolescents: a case study on prevalence of risk factors from Sabarkantha District of Gujarat, India. Indian J Community Med 2018;43(Suppl 1):S33-7.

[5] Obesity. In: The free dictionary. https://medicaldictionary.thefreedictionary.com/obesity

[6] Defining Childhood Obesity. Overweight \& Obesity. CDC https://www.cdc.gov/obesity/childhood/ defining.html

[7] WHO Physical activity and young people. WHO. http://www.who.int/dietphysicalactivity/factsheet_you ng_people/en/

[8] Examples of moderate and vigorous physical activity. Obesity Prevention $\quad$ Source 2012 https://www.hsph.harvard.edu/obesity-preventionsource/moderate-and-vigorous-physical-activity.

[9] Adolescent health and development child and adolescent health unit department of family health gender and life course (FGL). World Health Organization http://www.searo.who.int/entity/child_adolescent/topi cs /adolescent_health/en

[10] https://www.who.int/news-room/factsheets/detail/noncommunicable-diseases

[11] Oxford Dictionaries. Definition of determinant. Oxford University Press 2020: p. 4. http://www.oxforddictionaries.com/de.

[12] https://www.researchgate.net/figure/WHO-Asian-BMIclassification_tbl1_296026141 